\title{
Highly Porous Defective Carbons Derived from Seaweed Biomass as Efficient Electrocatalysts for Oxygen Reduction in both Alkaline and Acidic Media
}

Yajuan $\mathrm{Hao}^{\mathrm{a}, \mathrm{b}}$, Xu Zhang, ${ }^{\mathrm{a}, \mathrm{b}}$, Chen Wang ${ }^{\mathrm{a}, \mathrm{b}}$, Ping Liü ${ }^{\mathrm{a}, \mathrm{b}}$, Kai Chen ${ }^{\mathrm{a}, \mathrm{b}}$, Dongying Zhou $^{\mathrm{a}, \mathrm{b}}$, Lai Feng ${ }^{\mathrm{a}, \mathrm{b}, *}$, Zdeněk Slanina ${ }^{\mathrm{c}, *}$

a Soochow Institute for Energy and Materials InnovationS (SIEMIS), College of Physics, Optoelectronics and Energy \& Collaborative Innovation Center of Suzhou Nano Science and Technology, Soochow University, Suzhou 215006, China

b Jiangsu Key Laboratory of Advanced Carbon Materials and Wearable Energy Technologies, Soochow University, Suzhou 215006, China

${ }^{\mathrm{c}}$ Department of Chemistry and Biochemistry, University of Arizona, Tucson, Arizona 85721-0041, United States

*Email: fenglai@suda.edu.cn

KEYWORDS: Undoped carbon catalyst, Defective, Porous, Oxygen reduction reaction, Alkaline and acidic media 
Abstract: Very recently, a variety of undoped carbons have been employed as electrocatalysts for the oxygen reduction reaction (ORR), based on the defect mechanism. Nevertheless, the defective carbon catalyst with sufficiently high ORR activity is still very rare. In this work, we report a series of defective carbon catalysts prepared through a facile and scalable "N-doping-removal” process using seaweed biomass sodium alginate (SA) as precursor. Our systematic studies reveal that the defect content, porosity characteristic and conductivity of defective carbons can be finely tuned by manipulating the pyrolysis temperature and viscosity of precursor polymer SA, which significantly affect the ORR performance. In $0.1 \mathrm{M} \mathrm{KOH}$, compared to the commercial Pt/C catalyst, the optimized catalyst D-PC-1(900), with abundant ORR-active defects, a large surface area of $1377 \mathrm{~m}^{2} \mathrm{~g}^{-1}$, a $\mathrm{S}_{\text {micro/meso ratio of }}$ 0.6 and good conductivity, exhibited very comparable ORR activity and selectivity. In 0.5 $\mathrm{M} \mathrm{H}_{2} \mathrm{SO}_{4}$, considerable ORR activity was also observed for D-PC-1(900), which is among the highest reported for defective carbons and comparable to many of $\mathrm{N}$-doped carbons. Density functional theory calculations indicate that the carbon defect can create the active sites for ORR in acidic media. More importantly, in both alkaline and acidic media, D-PC-1(900) shows much better stability and methanol tolerance than those of the $\mathrm{Pt} / \mathrm{C}$ catalyst. All these results demonstrate that the seaweed biomass derived defective carbon is an excellent candidate for non-precious-metal ORR catalyst in various fuel cells. 


\section{Introduction}

To date, platinum (Pt)-based catalysts have been widely used as very efficient electrocatalysts for the oxygen reduction reactions (ORR) in both alkaline and acidic media [1,2], which are key reactions in various fuel cells [3,4]. However, Pt-based catalysts usually suffer from several unfavorable problems $[5,6]$, such as high-cost, poor durability, low tolerance to methanol (MeOH) crossover and $\mathrm{CO}$ poisoning effects, which impede their practical applications in fuel cells. To solve these bottleneck problems, low-cost and Pt-free catalysts with high catalytic activity and superior stability are highly desired. Thus, in recent years, a variety of carbon-based catalysts have been developed as inexpensive alternatives to Pt-based catalysts for ORR [7].

It has been well established that the catalytic performances of carbon catalysts can be significantly improved by using the heteroatom-doping strategy. It has been reported that a variety of heteroatoms such as $\mathrm{N}[8,9]$, $\mathrm{P}[10,11]$, S [12,13], $\mathrm{B}[14,15]$ can be homogeneously doped into porous carbons, leading to the introduction of new catalytic centers. In recent years, there have been numerous reports of the heteroatom-doped porous carbons with high catalytic activities, which are even comparable or superior to those of Pt/C catalyst [16-19]. On the other hand, it has been long believed that pristine or undoped carbons display very poor ORR catalytic activities.

However, a series of studies emerging very recently suggested a new mechanism, in which ORR is related to the specific carbon defects, such as edge pentagons, 585 
and 7557 motifs [20-27]. Nevertheless, there are only a limited number of cases reporting promising results, including undoped graphene quantum dots/graphene nanoribbons (GQDs/GNRs) hybrid [24], defective graphene (D-G) [27] and defective activated carbons (D-AC) [26]. These carbon catalysts demonstrated excellent or considerable ORR performance under alkaline conditions, which is more or less comparable to that of commercial $\mathrm{Pt} / \mathrm{C}$ catalyst, indicating their promising applications in the field of fuel cells.

Continuing with the exploitation of the potential of undoped carbons as ORR catalysts, we herein report a new class of defective carbon catalysts, which is prepared using seaweed biomass derived sodium alginate (SA) as precursor through a facile and scalable N-doping and removal process. This defective carbon exhibits good ORR catalytic activities as well as high selectivity and stability in both alkaline and acidic media, which are even comparable or superior to those of commercial Pt/C as well as most heteroatom-doped porous carbons. The excellent catalytic performance has been clearly attributed to the defects generated through the N-doping and removal process. This work hopefully provides a promising strategy to develop cheap and efficient defective carbon electrocatalysts in both alkaline and acidic media.

\section{Experimental section}

\subsection{Catalysts synthesis}

The N-doped carbon precursor (denoted as N-C-1) was prepared as follows. Briefly, $2.0 \mathrm{~g}$ of SA was dissolved in a mixed solution containing $120 \mathrm{~mL}$ deionized $\mathrm{H}_{2} \mathrm{O}$ and $40 \mathrm{~mL} \mathrm{NH}_{3} \cdot \mathrm{H}_{2} \mathrm{O}$ (28\%). Then, the mixture underwent a hydrothermal 
carbonization at $160^{\circ} \mathrm{C}$ for $4 \mathrm{~h}$, yielding a dark brown solution. The resulting solution was neutralized with $\mathrm{HCl}$ followed by a dialysis (1000KD) for 2 days to completely remove the salts (i.e., $\mathrm{NH}_{4} \mathrm{Cl}$ and $\mathrm{NaCl}$ ). This solution was freeze-dried for at least 24 h to produce N-C-1. Next, the dried N-C-1 was placed in the center of a quartz tube furnace. After pumping and purging the system with $\mathrm{Ar} / \mathrm{H}_{2}(5 \%) 3 \times$, the temperature was raised to $200{ }^{\circ} \mathrm{C}$ with a heating rate of $3{ }^{\circ} \mathrm{C} \mathrm{min}^{-1}$ and maintained for $2 \mathrm{~h}$. Then, the temperature was further raised to $900{ }^{\circ} \mathrm{C}$ with a heating rate of $10^{\circ} \mathrm{C} \min ^{-1}$ and held for $30 \mathrm{~min}$. After cooling down to room temperature, the product was washed with water and dried for characterizations.

To prepare the control catalyst D-PC-2(900), SA and $\mathrm{SiO}_{2}$ nanoparticles (with an average size of $15 \mathrm{~nm}$ ) were firstly uniformly mixed in a water solution with a mass ratio of 80:1. This solution was freeze-dried to produce the precursor. Then, the precursor was pyrolyzed at $900{ }^{\circ} \mathrm{C}$ for 30 min under $\mathrm{Ar} / \mathrm{H}_{2}(5 \%)$ atmosphere. The $\mathrm{SiO}_{2}$ nanoparticles that were used as hard templates can be removed by $0.1 \mathrm{M} \mathrm{HF}$. The final product of D-PC-2(900) was then obtained.

\subsection{Physical characterizations}

The X-ray diffraction (XRD) patterns of the carbon products were recorded on a Rigaku D/Max 2000 powder diffractometer with Cu Ka radiation (40 kV, 20 mA). X-ray photoelectron spectroscopy (XPS) studies were carried out with an ESCALAB 250 spectrometer using a monochromated $\mathrm{Al} \mathrm{K} \alpha$ excitation source. Fourier Transform infrared spectroscopy (FTIR) was measured on a Varian CP-3800 spectrometer in the wavenumber range of $400-4000 \mathrm{~nm}^{-1}$. The as-prepared carbon catalysts were 
characterized by the transmission electron microscope (TEM, FEI Tecnai F20) for the morphology and microstructure identifications. Raman spectra were recorded on a Micro-Raman spectroscopy system (Renishaw in Via-reflex, $633 \mathrm{~nm}$ excitation laser). Nitrogen adsorption-desorption isotherms at $-196{ }^{\circ} \mathrm{C}$ were measured on an adsorption volumetric analyzer ASAP 2020 manufactured by Micromeritics, Inc. (Norcross, Georgia, USA). All samples were degassed at $200{ }^{\circ} \mathrm{C}$ overnight prior to adsorption measurements. A part of the $\mathrm{N}_{2}$ sorption isotherm in the $\mathrm{P} / \mathrm{P}_{0}$ range of $0.005-0.05$ was fitted to the BET equation to estimate the BET surface area. The pore size distribution was obtained using the NLDFT model in the Micromeritics ASAP 2020 software package (assuming slit pore geometry). Micropore area $\left(\mathrm{S}_{\text {micro }}\right)$ was calculated using the t-plot method.

\subsection{Electrochemical measurements}

All electrochemical measurements were performed at room temperature on a potentiostat (CHI 760E, CH Instrument, Shanghai, China) and a rotating ring disk electrode system (RRDE-3A, ALS Co., Ltd, Japan) with a standard three electrode cell. A Pt wire and an $\mathrm{Hg} / \mathrm{HgO} / 1 \mathrm{M} \mathrm{OH}^{-}$electrode $(0.14 \mathrm{~V}$ vs NHE) or an $\mathrm{Ag} / \mathrm{AgCl} /$ saturated $\mathrm{KCl}$ solution electrode (0.1988 $\mathrm{V}$ vs $\mathrm{NHE}$ ) were used as the counter and reference electrode, respectively. A RDE with glassy carbon (GC) disk electrode (4 mm in diameter) and a rotating ring-disk electrode (RRDE, ALS Co., Ltd, Japan) with a Pt ring (5 mm inner diameter and $7 \mathrm{~mm}$ outer diameter) and a GC disk (4 mm diameter) are used as the substrate for the working electrodes. Before use, the GC electrodes in RDE/RRDE are polished using aqueous alumina suspension on 
polishing pad. In alkaline medium $(0.1 \mathrm{M} \mathrm{KOH})$, the potentials measured against $\mathrm{Hg} / \mathrm{HgO} / 1 \mathrm{M} \mathrm{OH}^{-}$electrode, was converted to the potential versus the reversible hydrogen electrode (RHE) according to $E_{\mathrm{RHE}}=E_{(\mathrm{Hg} / \mathrm{HgO} / 1 \mathrm{M} \mathrm{OH}-)}+0.0591 \mathrm{pH}+E_{(\mathrm{Hg} / \mathrm{HgO} / 1 \mathrm{M}}^{0}$ OH-) [28]. In acidic medium (0.5 $\left.\mathrm{M} \mathrm{H}_{2} \mathrm{SO}_{4}\right)$, the potentials measured against $\mathrm{Ag} / \mathrm{AgCl} /$ saturated $\mathrm{KCl}$ solution electrode, was converted to the potential versus the RHE according to $E_{\mathrm{RHE}}=E_{(\mathrm{Ag} / \mathrm{AgCl} / \text { saturated } \mathrm{KCl} \text { solution })}+0.0591 \mathrm{pH}+E^{0}(\mathrm{Ag} / \mathrm{AgCl} /$ saturated $\mathrm{KCl}$ solution) [29].

To fabricate the catalyst-modified working electrode, the catalyst ink was prepared by ultrasonically dispersing the as-prepared carbon catalyst (5 $\mathrm{mg}$ ) in a solution containing $95 \mu \mathrm{L}$ Nafion (5 wt\%) solution and $350 \mu \mathrm{L}$ ethanol. The as-prepared catalyst ink was casted onto the fresh surface of the GCE (with a diameter of $4 \mathrm{~mm}$ ).The Pt/C catalyst (10 wt\% Pt on graphitized carbon, Sigma-Aldrich) ink was prepared in the same way. The catalyst loading on RDE and RRDE is $400 \mu \mathrm{g}$ $\mathrm{cm}^{-2}$ for carbons while $40 \mu \mathrm{g}_{\mathrm{Pt}} \mathrm{cm}^{-2}$ for the Pt/C catalyst.

ORR performance of the catalysts was investigated via cyclic voltammogram (CV) and linear sweep voltammogram (LSV) in $\mathrm{O}_{2}$-saturated $0.1 \mathrm{M} \mathrm{KOH}$ and $0.5 \mathrm{M}$ $\mathrm{H}_{2} \mathrm{SO}_{4}$ solutions, respectively. The scan rate was $25 \mathrm{mV} \mathrm{s}^{-1}$ for $\mathrm{CV}$ and $5 \mathrm{mV} \mathrm{s}^{-1}$ for LSV tests. Oxygen reduction current was evaluated by subtracting the background capacitive current, which was measured by scanning the electrode in a $\mathrm{N}_{2}$-saturated $0.1 \mathrm{M} \mathrm{KOH}$ or $0.5 \mathrm{M} \mathrm{H}_{2} \mathrm{SO}_{4}$ solution under the same conditions. The electron transfer number (n) was calculated using the Koutecky-Levich (K-L) equations [30]:

(1) $\frac{1}{J}=\frac{1}{J_{K}}+\frac{1}{J_{L}}=\frac{1}{J_{K}}+\frac{1}{B \omega^{1 / 2}}$ 
(2) $B=0.20 n F C_{o} D_{o}{ }^{2 / 3} v^{-1 / 6}$

where $J$ is the measured current density, $J_{k}$ is the kinetic current density, $B$ is the Levich constant, $\omega$ is the angular velocity of the rotating electrode, $n$ is the overall number of electrons transferred in the ORR process, $F$ is the Faraday constant (96485 $\left.\mathrm{C} \mathrm{mol}^{-1}\right)$, and $v$ is the kinetic viscosity $\left(0.01 \mathrm{~cm}^{2} \mathrm{~s}^{-1}\right)$ of the electrolyte. $C_{0}$ is the bulk concentration $\left(1.26 \times 10^{-6} \mathrm{~mol} \mathrm{~cm}{ }^{-3}\right.$ in $0.1 \mathrm{M} \mathrm{KOH}$ and $1.13 \times 10^{-6} \mathrm{~mol} \mathrm{~cm}^{-3}$ in $0.5 \mathrm{M}$ $\left.\mathrm{H}_{2} \mathrm{SO}_{4}\right)$ of $\mathrm{O}_{2}, \mathrm{D}_{0}$ is the diffusion coefficient $\left(1.93 \times 10^{-5} \mathrm{~cm}^{2} \mathrm{~s}^{-1}\right.$ in $0.1 \mathrm{M} \mathrm{KOH}$ and $1.8 \times 10^{-5} \mathrm{~cm}^{2} \mathrm{~s}^{-1}$ in $\left.0.5 \mathrm{M} \mathrm{H}_{2} \mathrm{SO}_{4}\right)$ of $\mathrm{O}_{2}[31,32]$.

Rotating ring-disk electrode (RRDE) tests for ORR were measured with a scan rate of $5 \mathrm{mV} \mathrm{s}^{-1}$, and the ring potential was set at 1.2-1.4 V (vs. RHE) for $\mathrm{H}_{2} \mathrm{O}_{2}$ production in the $\mathrm{O}_{2}$ saturated $0.1 \mathrm{M} \mathrm{KOH}$ and $0.5 \mathrm{M} \mathrm{H}_{2} \mathrm{SO}_{4}$ solutions, respectively. The electron transfer number $n$ and the production yield of $\mathrm{HO}_{2}{ }^{-}$in $0.1 \mathrm{M} \mathrm{KOH}$ or $\mathrm{H}_{2} \mathrm{O}_{2}$ in $0.5 \mathrm{M} \mathrm{H}_{2} \mathrm{SO}_{4}\left(\mathrm{HO}_{2}{ }^{-} \%\right.$ or $\left.\mathrm{H}_{2} \mathrm{O}_{2} \%\right)$ were determined using the following equations:

(3) $\mathrm{HO}_{2}^{-} \%$ or $\mathrm{H}_{2} \mathrm{O}_{2} \%=200 \times \frac{I_{r} / N}{I_{d}+I_{r} / N}$

(4) $n=4 \times \frac{I_{d}}{I_{d}+I_{r} / N}$

where $I_{d}$ is the disk current, $I_{r}$ is the ring current, and $\mathrm{N}$ is the current collection efficiency of the Pt ring, which is 0.424 provided by the manufacturer.

For stability tests, the $\mathrm{i}-\mathrm{t}$ chronoamperometric measurements were performed in either $\mathrm{O}_{2}$-saturated $0.1 \mathrm{M} \mathrm{KOH}$ or $0.5 \mathrm{M} \mathrm{H}_{2} \mathrm{SO}_{4}$ at $0.6 \mathrm{~V}$ (vs RHE) for 2.5-5.5 h with a rotation rate of $400 \mathrm{rpm}$. For methanol crossover effect tests, the $\mathrm{i}-\mathrm{t}$ chronoamperometric response at $0.6 \mathrm{~V}$ (vs. RHE) was recorded by RDE tests with a 
rotation rate of $1600 \mathrm{rpm}$ at the same potentials, and followed by the introduction of methanol (3 M).

Electrochemical impedance spectroscopy (EIS) measurements were carried out in $0.1 \mathrm{M} \mathrm{KOH}$ and $0.5 \mathrm{M} \mathrm{H}_{2} \mathrm{SO}_{4}$, respectively, on an IM6e Electrochemical Workstation (ZAHNER, Germany) with the frequency sweeping from 50000 to $0.01 \mathrm{~Hz}$, where the AC voltage amplitude was set at $5 \mathrm{mV}$. Before the EIS scanning, the electrode was equilibrated at the corresponding bias potential for $120 \mathrm{~s}$.

\section{Results and discussion}

\subsection{Synthesis of defective carbon catalysts}

Sodium alginate (SA, medium viscosity) is chosen as precursor for the synthesis of defective carbon ORR catalysts based on the following considerations: (i) SA derived from abundant seaweed biomass is cheap, green and readily available; (ii) SA bears abundant carboxyl and hydroxyl groups, which can be removed from the polymeric matrix through a pyrolysis, resulting in 3D carbon materials with high porosity and good electrical conductivity [33-36]; (iii) SA can be chemically modified under mild conditions, which allows N-doping at low temperature $\left(<200{ }^{\circ} \mathrm{C}\right)$. Scheme 1 depicts a typical preparation. Firstly, precursor polymer SA was carbonized via a hydrothermal process at $160{ }^{\circ} \mathrm{C}$ in the presence of $\mathrm{NH}_{3} \cdot \mathrm{H}_{2} \mathrm{O}$, yielding an $\mathrm{N}$-doped carbon product denoted as $\mathrm{N}-\mathrm{C}-1$. Next, the N-dopants in $\mathrm{N}-\mathrm{C}-1$ was removed via a high-temperature pyrolysis (i.e., $700-900{ }^{\circ} \mathrm{C}$ ) under $\mathrm{Ar} / \mathrm{H}_{2}$ atmosphere, thus yielding porous defective carbons (D-PC-1(x), $x=700,800$ and 900) containing trace or negligible $\mathrm{N}$-species. To further study the effect of the defects generated via the 
$\mathrm{N}$-doping and removal process, a control catalyst (D-PC-2(900)) was prepared via a one-step pyrolysis of $\mathrm{SA}$ using $\mathrm{SiO}_{2}$ nanoparticles as hard template. In addition, to examine whether the viscosity factor of precursor polymer is essential for preparing the defective carbon catalysts, another control catalyst D-PC-3(900) was prepared from SA with low viscosity using the same "N-doping-removal” method.

Scheme 1. Schematic illustration the preparation with an N-doping-removal process.

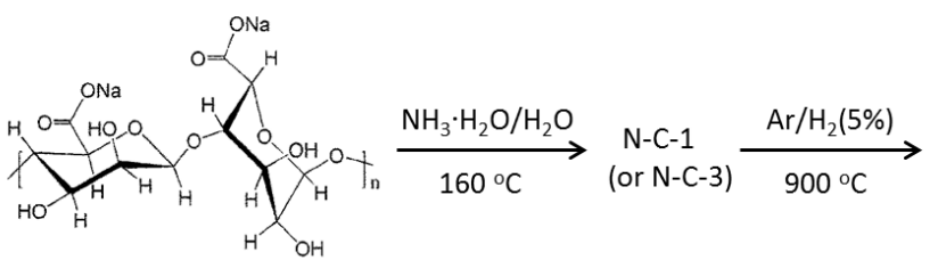

SA

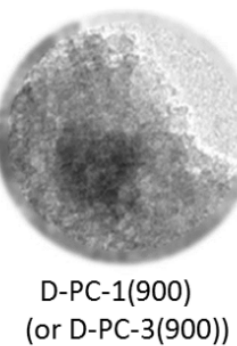

\subsection{Electrochemical measurements}

ORR catalytic activities of these as-prepared carbon catalysts were evaluated by means of cyclic voltammetry (CV) and linear sweep voltammetry (LSV), respectively, in $\mathrm{O}_{2}$-saturated $0.1 \mathrm{M} \mathrm{KOH}$. As shown Fig. 1a, all CV curves show evident ORR peaks, indicating that all these carbon catalysts are ORR active in alkaline medium. Furthermore, as suggested by LSV measurements (Fig. 1b), D-PC-1(900) exhibits the highest ORR activity in terms of an onset potential ( $\left.E_{\text {onset }}\right)$ of $1.01 \mathrm{~V}$, a half-wave potential $\left(E_{1 / 2}\right)$ of $0.83 \mathrm{~V}$ and a limiting current density $\left(J_{L}\right)$ of $-5.43 \mathrm{~mA} \mathrm{~cm}{ }^{-2}$. All these values are very comparable to those of commercial Pt/C catalyst (E onset: $1.01 \mathrm{~V}$, $E_{1 / 2}: 0.84 \mathrm{~V}$ and $J_{L}:-5.35 \mathrm{~mA} \mathrm{~cm}{ }^{-2}$, all close to the reference data with similar $\mathrm{Pt}$ loading) $[17,37,38]$ as well as many of heteroatom-doped carbon catalysts (see Table S4). In contrast, the ORR activity of D-PC-2(900) is among the poorest. As for other carbon catalysts, though D-PC-1(800) and D-PC-3(900) prepared with 
N-doping-removal process are slightly inferior to D-PC-1(900), they are much better than D-PC-2(900). These results indicate that the $\mathrm{N}$-doping-removal process is essential in achieving the defective carbons with high ORR catalytic activity.
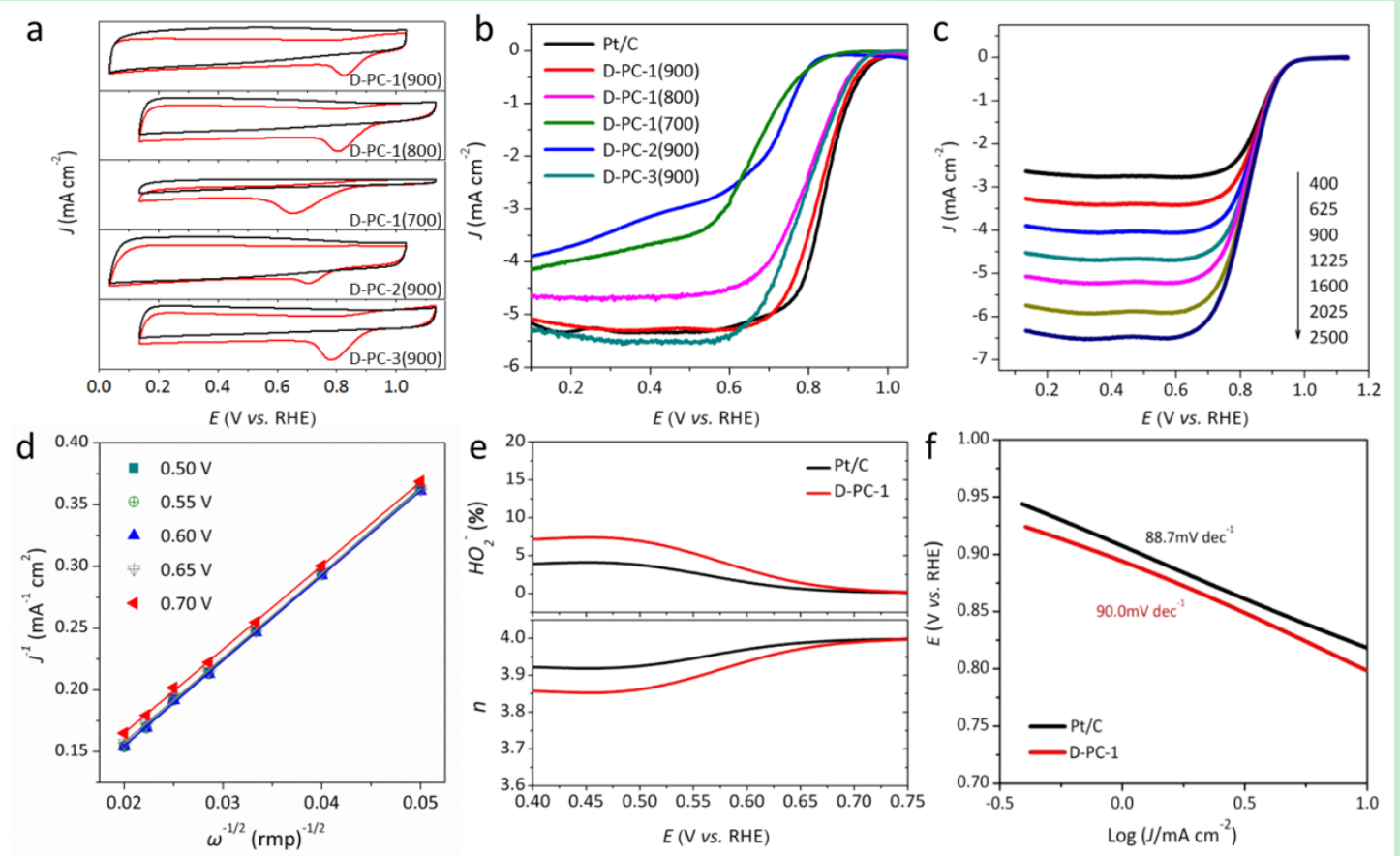

Figure 1. (a) CV curves of D-PC-1(900) and D-PC-2(900) compared with Pt/C (40 $\mu \mathrm{g}_{\mathrm{Pt}} \mathrm{cm}^{-2}$ ) in $\mathrm{O}_{2}$ or $\mathrm{N}_{2}$-saturated $0.1 \mathrm{M} \mathrm{KOH}$. (b) LSV curves of D-PC-1(900) and D-PC-2(900) compared with Pt/C in $\mathrm{O}_{2}$-saturated $0.1 \mathrm{M} \mathrm{KOH}$ at $1600 \mathrm{rpm}$. (c) LSV curves of D-PC-1(900) at different rotation speeds (rpm) in $\mathrm{O}_{2}$-saturated $0.1 \mathrm{M} \mathrm{KOH}$. (d) The Koutecky-Levich (K-L) plots for D-PC-1(900) at different potentials. (e) The plots of $\mathrm{HO}_{2}^{-}$yield (up) and $n$ value (down) against electrode potential for D-PC-1(900) and Pt/C in $\mathrm{O}_{2}$-saturated 0.1 M KOH. (f) Tafel plot of D-PC-1(900) in $\mathrm{O}_{2}$-saturated $0.1 \mathrm{M} \mathrm{KOH}$ compared with that of $\mathrm{Pt} / \mathrm{C}$. The loading of all carbon catalysts is $400 \mu \mathrm{g} \mathrm{cm}^{-2}$. The Pt loading is $40 \mu \mathrm{g}_{\mathrm{Pt}} \mathrm{cm}^{-2}$.

To determine whether the ORR on D-PC-1(900) and D-PC-2(900) occur through a four-electron pathway and compare with Pt/C, LSV curves at different rotation rates 
were measured (Fig. 1c, S1a, S2a). Based on the K-L plots $\left(J^{-1}\right.$ vs. $\omega^{-1 / 2}$ in Fig. 1 d, S1b, S2b), in a potential range of 0.50-0.70 V (vs. RHE), the electron-transfer number (n) was calculated to be 3.87-3.98, 2.64-3.12, 3.96-4.0 for D-PC-1(900), D-PC-2(900) and $\mathrm{Pt} / \mathrm{C}$, respectively. This result was further validated by rotating ring-disk electrode (RRDE) measurements (see Fig. S3). Based on the measured ring current and disk current, the electron-transfer number was calculated to be 3.86-4.0 for D-PC-1(900) in a potential range of 0.40-0.75 V (vs. RHE, see Fig. 1e). These values are in good agreement with that obtained from Koutecky-Levich plot (K-L plot), suggesting a four-electron pathway dominant in the ORR catalyzed by D-PC-1(900) in alkaline medium. In addition, the RRDE measurements reveal that the production of $\mathrm{HO}_{2}{ }^{-}$is highly suppressed on D-PC-1(900) with a yield below $\sim 6.9 \%$ over the scanned potential range (0.40-0.75 V), almost comparable to that obtained on the $\mathrm{Pt} / \mathrm{C}$ (see Fig. 1e, a value of $\sim 3.8 \%$, close to the reference data) [39]. Thus, these results suggest that D-PC-1(900) shows a high ORR catalytic efficiency in alkaline medium. Moreover, D-PC-1(900) demonstrates a Tafel slope of $90.0 \mathrm{mV} \mathrm{dec}^{-1}$ (see Fig. 1f),

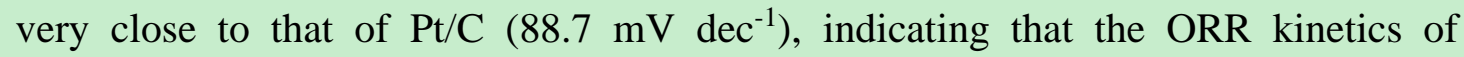
D-PC-1(900) is similar to that of Pt/C.

The ORR catalytic activities of these carbon catalysts were also tested in acidic medium (0.5 $\mathrm{M} \mathrm{H}_{2} \mathrm{SO}_{4}$ ), and similar results were obtained. As shown in Fig. 2a, D-PC-1(900) exhibits a considerable ORR activity in terms of an $E_{\text {onset }}$ of $0.82 \mathrm{~V}$, an $E_{1 / 2}$ of $0.60 \mathrm{~V}$ and a high $J_{L}$ of $-4.60 \mathrm{~mA} \mathrm{~cm}^{-2}$, followed by D-PC-1(800) with a negatively shifted $E_{1 / 2}(0.63 \mathrm{~V})$ but slightly negatively shifted $E_{\text {onset }}(0.80 \mathrm{~V})$. Note that 
the $E_{\text {onset }}$ of D-PC-1(900) and D-PC-1(800) are even comparable to that (E $E_{\text {onset }}: 0.83$ V) of $\mathrm{Pt} / \mathrm{C}$ catalyst, though their $E_{1 / 2}$ are ca. $100-130 \mathrm{mV}$ more negative. These $E_{\text {onset }}$ and $E_{1 / 2}$ values are also comparable to or even better than those reported for many of typically heteroatom-doped carbon catalysts (see Table S5). These results demonstrate that the defective carbon catalysts D-PC-1(900) and D-PC-1(800) are among the best for the non-metal catalysts in acidic medium. Additionally, Fig. $2 \mathrm{~b}$ gives the LSV curves of D-PC-1(900) measured at various rotating rates compared with Pt/C (Fig. S4), showing rapidly increased current densities with the increase in rotation speed. The electron transfer number $(n)$ was calculated to be 3.72-3.81 in a potential range of 0.3-0.5V (vs. RHE) using K-L plots (Fig. 2c). This result was confirmed by RRDE measurements (Fig. S5), which suggest an electron transfer number (n) of 3.86-3.94 and $\mathrm{H}_{2} \mathrm{O}_{2}$ yield of 2.9-7.2\% in the similar potential range (i.e., $0.20-0.55 \mathrm{~V}$, see Fig. 2d). Thus, the combined study of RDE and RRDE suggests a four-electron pathway dominated in the ORR on D-PC-1(900) in acidic medium. As shown in Fig. 2e, the Tafel slope of D-PC-1(900) is calculated to be $56.8 \mathrm{mV} \mathrm{dec}^{-1}$ at low potentials, close to that of $\mathrm{Pt} / \mathrm{C}$ (53.8 $\left.\mathrm{mV} \mathrm{dec}^{-1}\right)$, indicating their similar ORR kinetics in acidic medium. Noteworthy is that D-PC-2(900) shows almost negligible ORR activity under the same condition, which again demonstrates the importance of the $\mathrm{N}$-doping-removal process in preparation of defective carbon catalysts with high ORR activity. 

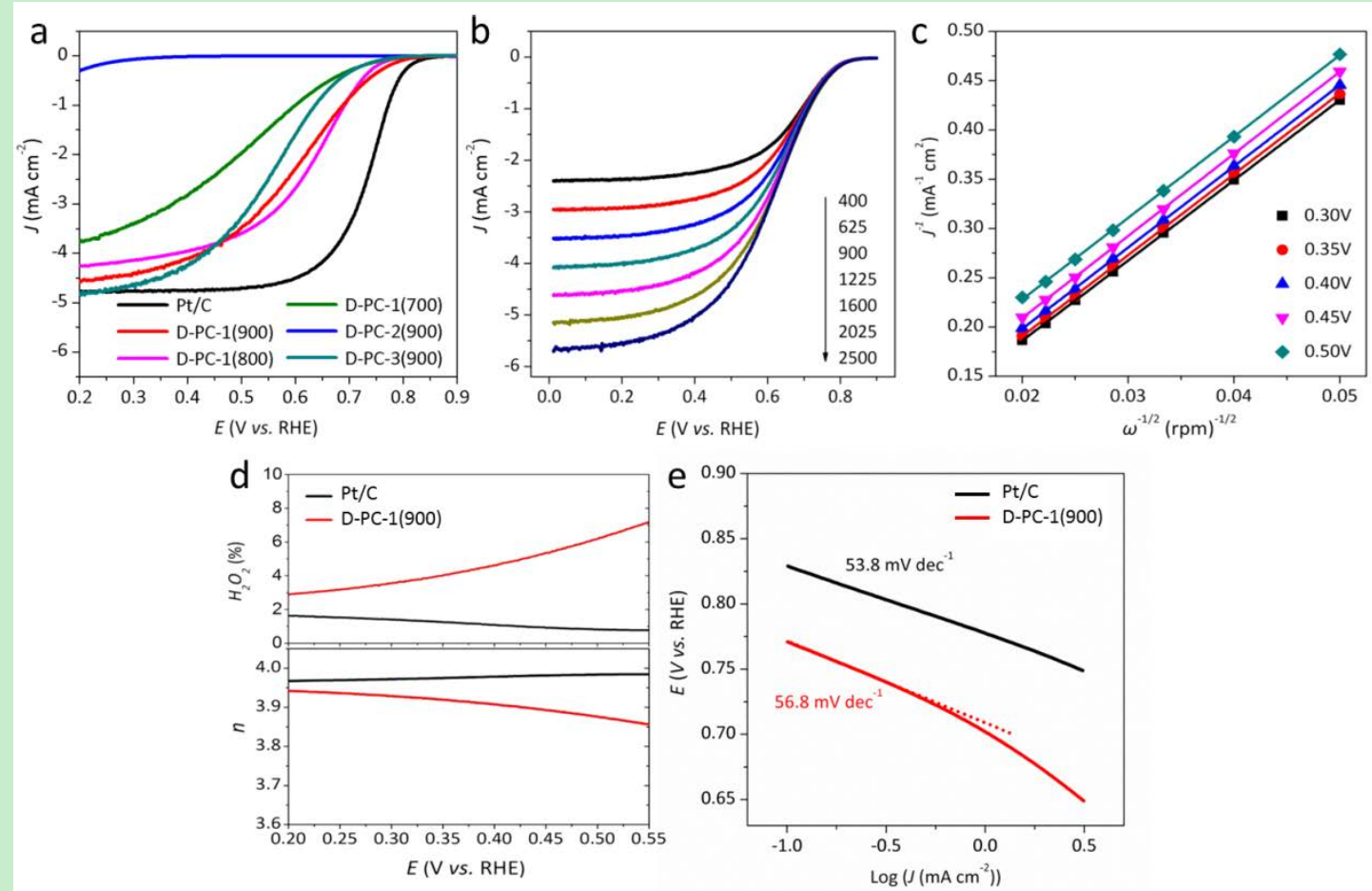

Figure 2. (a) LSV curves of D-PC-1(900) and D-PC-2(900) compared with Pt/C in $0.5 \mathrm{M} \mathrm{H}_{2} \mathrm{SO}_{4}$ at $1600 \mathrm{rpm}$. (b) LSV curves of D-PC-1(900) at different rotation speeds (rpm) in $0.5 \mathrm{M} \mathrm{H}_{2} \mathrm{SO}_{4}$. (c) The corresponding Koutecky-Levich (K-L) plots. (d) The plots of $\mathrm{HO}_{2}^{-}$yield (up) and $n$ value (down) against electrode potential for D-PC-1(900) compared with those of $\mathrm{Pt} / \mathrm{C}$ in $0.5 \mathrm{M} \mathrm{H}_{2} \mathrm{SO}_{4}$ (d) Tafel plot of D-PC-1(900) compared with that of $\mathrm{Pt} / \mathrm{C}$ in $0.5 \mathrm{M} \mathrm{H}_{2} \mathrm{SO}_{4}$. (The loading of all nonprecious catalysts is $400 \mu \mathrm{g} \mathrm{cm}^{-2}$. The Pt loading is $40 \mu \mathrm{gPt}_{\mathrm{Pt}}^{-2}$ ).

\subsection{Characterizations of defective carbon catalysts}

To investigate the reasons behind the good catalytic performance of D-PC-1(900), a series of physical characterizations were performed. Firstly, XRD and Raman measurements were performed to study their structural features. As shown in Fig. 3a, the carbon catalysts show similar XRD patterns with a broad peak around $2 \theta$ $\approx 25^{\circ}$, which corresponds to the (002) plane of graphitic carbon, indicating their 
partially graphitized structures. The carbon catalysts also show similar Raman spectra (Fig. 3b), in which two characteristic peaks observed at 1327 and $1590 \mathrm{~cm}^{-1}$ can be assigned to the D band and $\mathrm{G}$ band, respectively. The $\mathrm{D}$ band arises from the structural defects, while the $G$ band is closely related to the graphitic carbon phase with a sp ${ }^{2}$ electronic configuration $[40,41]$. Thus, the defect density in carbon catalyst can be estimated using the ratio of the $\mathrm{D}$ band to $\mathrm{G}$ band integrated intensities $\left(I_{D} / I_{G}\right)$ [42]. Among all these carbon catalysts, D-PC-1(900) shows the highest $I_{D} / I_{G}$ ratio (2.88), while D-PC-2(900) gives the lowest (2.24). Other catalysts show the $I_{D} / I_{G}$ ratios ranging from 2.71 to 2.53 . These results indicate the following facts: (i) defective structures are common in these carbon catalysts; (ii) the carbon catalysts prepared through the N-doping-removal process possess slightly more defects. The structural features of D-PC-1(900) and D-PC-2(900) were further examined by electronic and FT-IR spectroscopy techniques. As shown in the TEM and HR-TEM images (Fig. 3c, d and S6), D-PC-1(900) and D-PC-2(900) exhibit similar cotton-like morphologies with abundant meso- and micropores in the carbon matrix. The ring-like patterns shown in the selected-area electron diffraction (SAED) images indicate their amorphous nature, in good agreement with the messy lattice fringes observed in HR-TEM image. In addition, D-PC-1(900) and D-PC-2(900) display featureless and similar FT-IR spectra (see Fig. S7). The broad band centered at 1585 $\mathrm{cm}^{-1}$ can be assigned to the in-plane vibration of aromatic carbon skeleton $(C=C)$ [24], while another weak but broad band at 1100-1280 might be attributed to the presence of a trace of C-O groups [43], indicative of the carbon nanostructures with relatively 
high degree of graphitization. These results suggest that D-PC-1(900) and D-PC-2(900) share the similar structural features, though the former is slightly more defective than the latter as revealed by XRD.
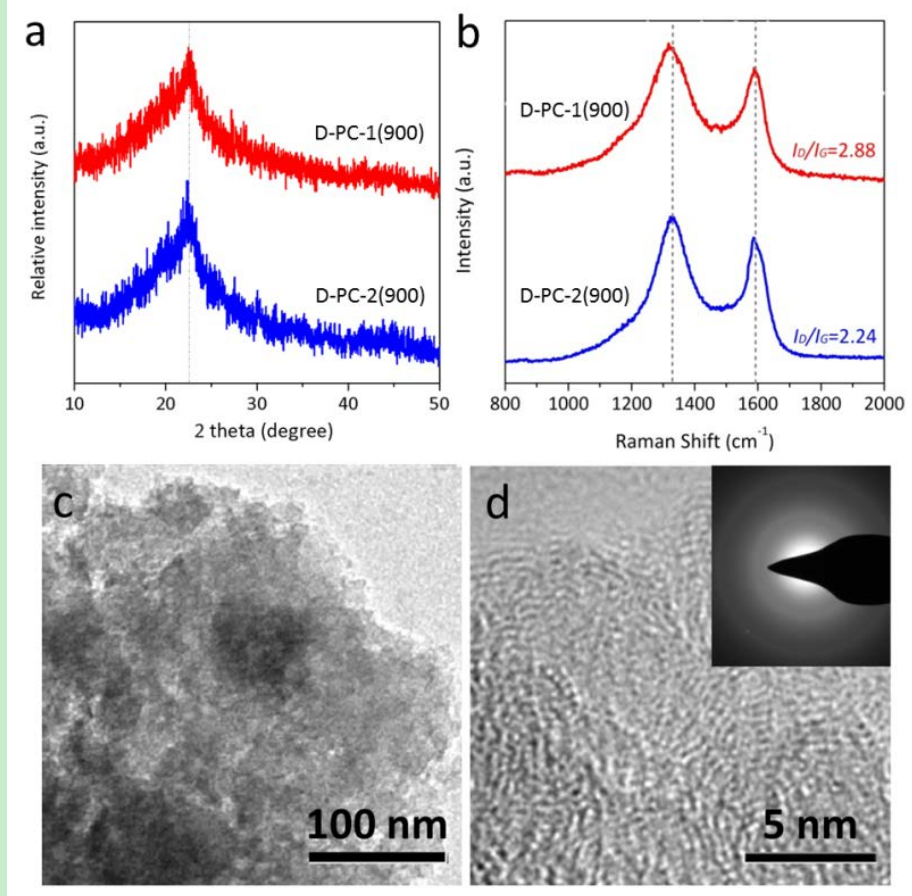

Figure 3. (a,b) XRD and Raman spectra of D-PC-1(900) and D-PC-2(900). (c,d) TEM images of D-PC-1(900) at different magnifications.

The porous characteristics and BET specific areas of the carbon catalysts were evaluated using $\mathrm{N}_{2}$ adsorption-desorption measurements. As shown in Fig. 4, all samples exhibit a sharp $\mathrm{N}_{2}$ uptake at low pressure $\left(P / P_{0}<0.001\right)$ and a relatively smooth plateau at middle pressure $\left(P / P_{0}=0.001-0.4\right)$, indicative of the presence of abundant micropores that are ascribed to the vacancies left by the release of $\mathrm{H}_{2} \mathrm{O}$ and $\mathrm{CO}_{2}$ during the hydrothermal and pyrolysis processes $[35,44]$. In the medium to high pressure regions $\left(P / P_{0}=0.4-1.0\right)$, all samples except for D-PC-1(700) display a small hysteresis loop, suggesting the presence of plenty of mesopores, which might be related to the efficient removal of the $\mathrm{N}$-dopants (for D-PC-1(900, 800) and 
D-PC-3(900)) or hard template of $\mathrm{SiO}_{2}$ nanoparticles (for D-PC-2(900)). Such results can be confirmed by pore size distribution (PSD) results calculated using nonlocal density functional theory (NL-DFT) (Fig. S8): All samples possess abundant micropores (around 0.6-2.0 nm). Except for sample D-PC-1(700), all samples also show more or less mesopores with pore sizes distributed in a wide range of 2-50 nm. As the large microporous surface area is reported to be critical for the formation of the active sites and mesoporous structure for efficient mass transport, the hierarchical porous characteristics has been believed to be beneficial for ORR process. The BET specific areas of all these carbon samples along with their micro- and mesopores areas calculated using t-plot method are listed in Table 1. It can be seen that (i) all samples except for D-PC-1(700) possess large BET areas over $1200 \mathrm{~m}^{2} \mathrm{~g}^{-1}$; (ii) D-PC-1(900) and D-PC-2(900) possess very similar porous characteristics including similar BET areas and comparable ratios of $\mathrm{S}_{\text {micro }} / \mathrm{S}_{\text {meso }}$ (i.e., 0.6 vs 0.9 ); (iii) the ratio of $\mathrm{S}_{\text {micro }} / \mathrm{S}_{\text {meso }}$ is decreasing with the increase of pyrolysis temperature. For example, the catalysts prepared by the pyrolysis at $900{ }^{\circ} \mathrm{C}$ generally possess more mesopores than those prepared at $800-700{ }^{\circ} \mathrm{C}$. Nevertheless, since ORR activity of D-PC-1(800) is only slightly lower than that of the best D-PC-1(900), it appears that increasing the $\mathrm{S}_{\text {micro }} / \mathrm{S}_{\text {meso }}$ ratio from 0.6 to 3.6 induces insignificant effect on the ORR activity of the carbon catalysts with sufficient BET surface areas.

Table 1. Textural properties of D-PC-1(900) and D-PC-2(900).

\begin{tabular}{|c|c|c|c|c|c|}
\hline & N (at.\%) & $\mathrm{S}_{\mathrm{BET}}$ & $\mathrm{S}_{\text {micro }}$ & $S_{\text {meso }}$ & Ratio of \\
\hline \multicolumn{6}{|l|}{ Catalysts } \\
\hline & & $\left(m^{2} g^{-1}\right)^{a}$ & $\left(m^{2} g^{-1}\right)^{b}$ & $\left(m^{2} g^{-1}\right)^{c}$ & $\mathrm{~S}_{\text {micro }} / \mathrm{S}_{\text {meso }}$ \\
\hline
\end{tabular}




\begin{tabular}{lccccc}
\hline D-PC-1(900) & $<0.10$ & 1377 & 516 & 862 & 0.6 \\
\hline D-PC-1(800) & 1.98 & 1201 & 941 & 260 & 3.6 \\
\hline D-PC-1(700) & 3.94 & 732 & 583 & 149 & 3.9 \\
\hline D-PC-2(900) & --- & 1302 & 622 & 680 & 0.9 \\
\hline D-PC-3(900) & 0.83 & 1242 & 834 & 408 & 2.0 \\
\hline
\end{tabular}

${ }^{a}$ Surface areas $\left(\mathrm{S}_{\mathrm{BET}}\right)$ were calculated by the BET method.

${ }^{\mathrm{b}}$ Micropore areas $\left(\mathrm{S}_{\text {micro }}\right)$ were calculated using the t-plot method.

${ }^{c}$ Mesopore areas $\left(S_{\text {meso }}\right)$ were calculated from the difference of the BET surface area and micropore area $\left(\mathrm{S}_{\text {meso }}=\mathrm{S}_{\mathrm{BET}}-\mathrm{S}_{\text {micro }}\right)$.
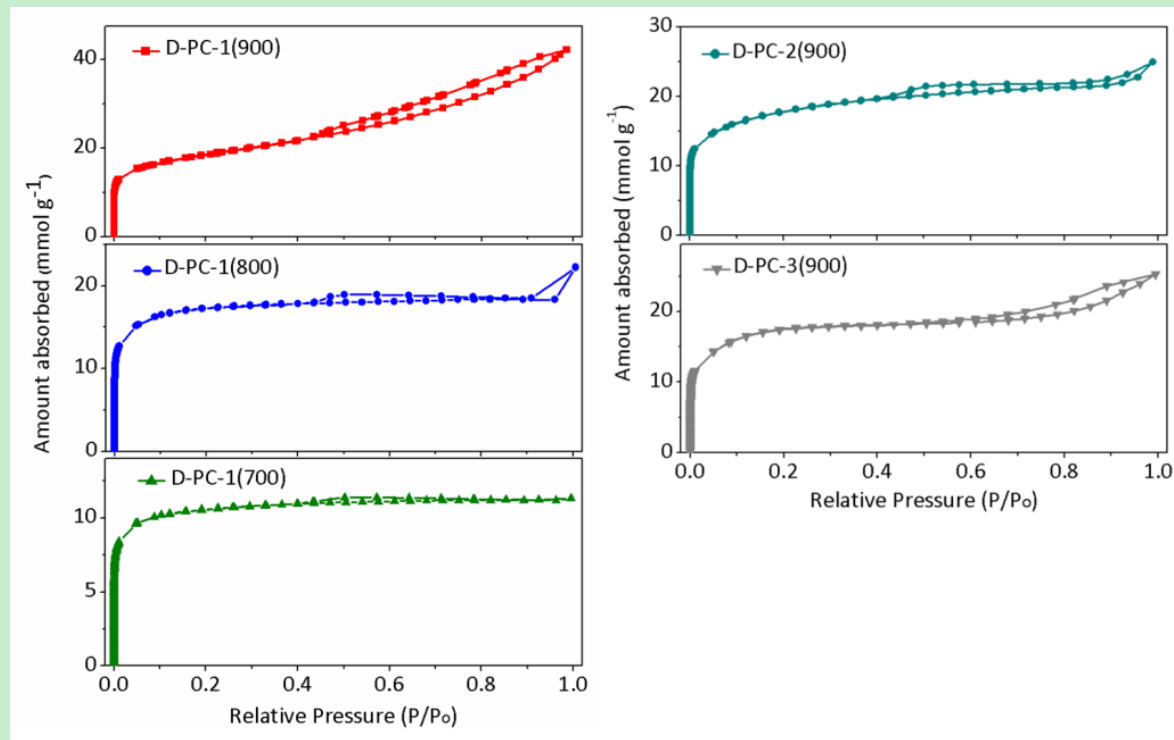

Figure 4. $\mathrm{N}_{2}$ adsorption-desorption isotherms of D-PC-1(900), D-PC-1(800), D-PC-1(700), D-PC-2(900) and D-PC-3(900).

Furthermore, the compositions of these carbon catalysts were explored by means of XPS (Fig. 5 and S9). The elemental contents estimated by XPS analyses are summarized in Table 1 and S1. It is clearly seen that the hydrothermally prepared precursors $\mathrm{N}-\mathrm{C}-1$ and $\mathrm{N}-\mathrm{C}-3$ possess a moderate $\mathrm{N}$-content of 5.2 and 7.8 at\%, 
respectively, indicating the successful $\mathrm{N}$-doping through the hydrothermal process. Nevertheless, the $\mathrm{N}$-content of $\mathrm{D}-\mathrm{PC}-1(900)$ is almost negligible $(<0.10$ at $\%)$, followed by D-PC-3(900) (0.83 at\%), D-PC-1(800) (1.98 at\%) and D-PC-1(700) (3.94 at\%). These results suggest that the $\mathrm{N}$-dopants can be more efficiently removed via the pyrolysis at higher temperature, resulting in more abundant defects in D-PC-1(900) and D-PC-3(900). Obviously, the high ORR activity of D-PC-1(900) is not originated from the $\mathrm{N}$ species because of the negligible $\mathrm{N}$-content on the carbon matrix surface but likely related to the specific defects generated by the $\mathrm{N}$-doping-removal process. The importance of the $\mathrm{N}$-doping-removal process can be further confirmed by the fact that D-PC-2(900) displays very poor ORR activity, though it also possesses no $\mathrm{N}$-content and shares similar structural features as discussed above. In addition, the high-resolution $\mathrm{N}$ 1s spectra of $\mathrm{D}-\mathrm{PC}-1(\mathrm{x})(\mathrm{x}=700,800)$ reveal the presence of pyridinic, pyrrolic and graphitic N-species $[45,46]$, which have been reported to be highly ORR active species [47]. Hence the inferior ORR activities of D-PC-1(x) $(x=700,800)$ might indicate that these $\mathrm{N}$-species are less efficient in promoting the ORR activities of carbon catalysts, as compared to the defects generated by the N-doping-removal process. 


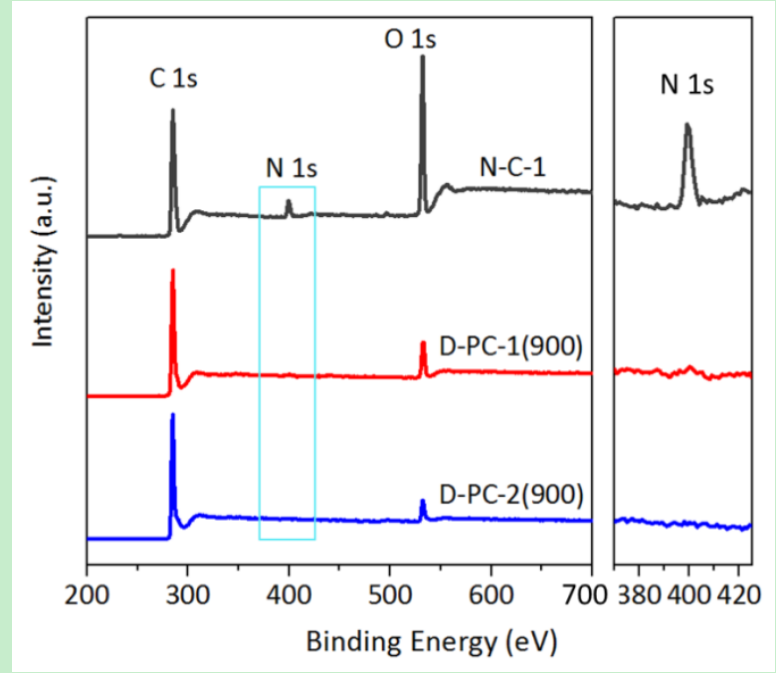

Figure 5. XPS survey spectra of N-C-1, D-PC-1(900) and D-PC-2(900) (the highlighted area was enlarged in the right of this figure).

Moreover, it is also noted that the two defective carbons D-PC-1(900) and D-PC-3(900), which were prepared using SA with medium and low viscosities as precursors, respectively, show different ORR activities in either alkaline or acidic medium. To better understand how the viscosity factor of precursor polymer (SA) affects the ORR activities of defective carbons, electrochemical impedance spectroscopy (EIS) measurements were conducted on D-PC-1(900) and D-PC-3(900), respectively, in both alkaline and acidic media. The Nyquist plots including experimental (symbols) and fitted data (solid lines) are shown in Fig. 6. The inset presents the corresponding equivalent circuit, which consists of the electrolyte resistance $\left(R_{s}\right)$, catalyst film resistance $\left(R_{c}\right)$, charge transfer resistance $\left(R_{t}\right)$ and constant phase elements of the catalyst layer and double layer (C1 and C2) [48]. The fitted data are summarized in Table 2. It can be seen that each Nyquist plot measured in either alkaline or acidic medium is composed of two semicircles at high and low frequencies, which are associated to $\mathrm{R}_{\mathrm{c}}$ and $\mathrm{R}_{\mathrm{t}}$, respectively. Obviously, D-PC-1(900) 
always exhibits smaller $\mathrm{R}_{\mathrm{c}}$ and $\mathrm{R}_{\mathrm{t}}$ (see Table 2) irrespective of the electrolyte variety (i.e., alkaline or acidic), suggesting a higher electron conductivity of the catalyst film and faster charge transfer on the D-PC-1(900)-electrolyte interface. Therefore, it is reasonable to propose that the precursor polymer SA with medium viscosity yielded the defective carbon with higher electron conductivity, which combining the more abundant mesoporous structures may account for the better ORR activity of D-PC-1(900).
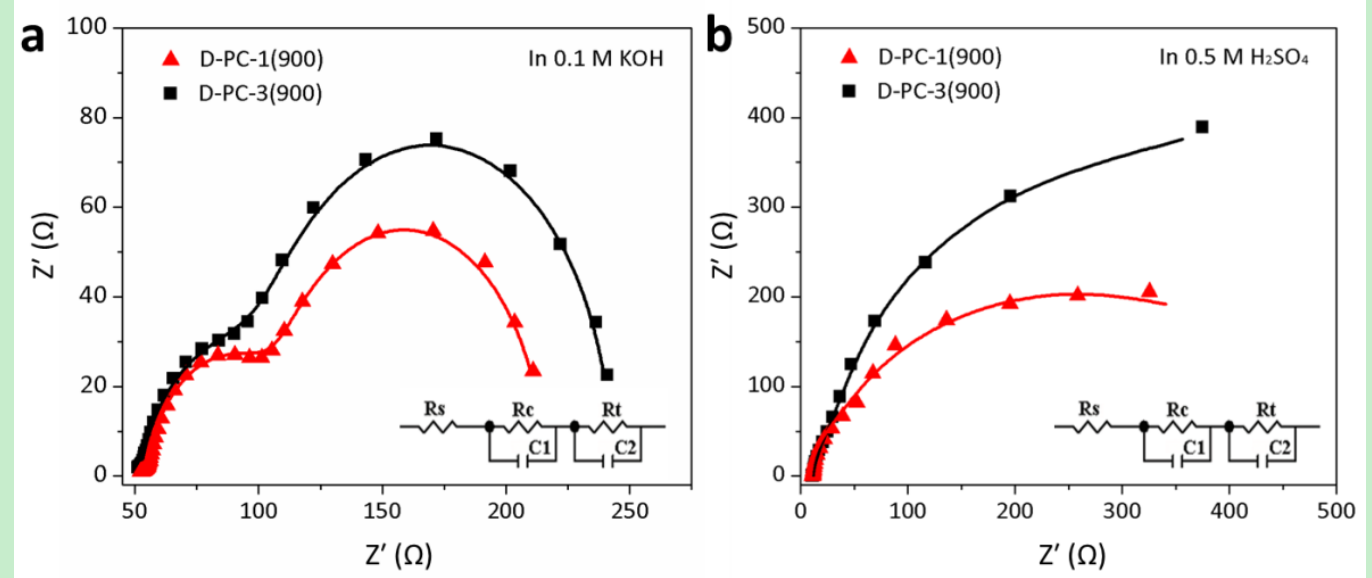

Figure 6. Electrochemical impedance spectra (EIS) of D-PC-1(900) and D-PC-3(900) for the ORR at their onset potential in (a) $\mathrm{O}_{2}$-saturated $0.1 \mathrm{M} \mathrm{KOH}$ solution and (b) $\mathrm{O}_{2}$-saturated $0.5 \mathrm{M} \mathrm{H}_{2} \mathrm{SO}_{4}$ solution Inset shows equivalent circuit used to interpret the data.

Table 2. Impedance spectra fitting results for the ORR on D-PC-1(900) and D-PC-3(900) in alkaline and acidic media, respectively.

\begin{tabular}{|c|c|c|c|c|c|c|c|}
\hline Samples & $\mathrm{R}_{\mathrm{S}}(\Omega)$ & $\mathrm{C}_{1}\left(10^{-3} \Omega\right)$ & $\mathrm{n}_{1}$ & $\mathrm{R}_{2}(\Omega)$ & $\mathrm{C}_{2}\left(10^{-3} \Omega\right)$ & $\mathrm{n}_{2}$ & $\mathrm{R}_{3}(\Omega)$ \\
\hline D-PC-1(900) & 54.5 & 1.43 & 0.86 & 56.54 & 13.90 & 1.01 & 103.8 \\
\hline D-PC-3(900) $^{\mathrm{a}}$ & 52.0 & 1.83 & 0.83 & 57.24 & 8.40 & 1.04 & 132.9 \\
\hline
\end{tabular}




\begin{tabular}{|c|c|c|c|c|c|c|c|}
\hline D-PC-1(900) & 9.5 & 2.44 & 1.19 & 12.66 & 1.51 & 0.91 & 473.7 \\
\hline D-PC-3(900) & 11.7 & 4.73 & 0.88 & 47.37 & 2.85 & 1.08 & 658.3 \\
\hline
\end{tabular}

${ }^{\mathrm{a}}$ In $0.1 \mathrm{M} \mathrm{KOH} ;{ }^{\mathrm{b}}$ In $0.5 \mathrm{M} \mathrm{H}_{2} \mathrm{SO}_{4}$.

In addition, to better understand the less-explored catalytic mechanism of defective carbon in acidic medium, a series of DFT calculations were performed with Gaussian 09 program package[49]. Particularly, two typical defect models (A, see Fig. 7 and $\mathbf{B}$, see Fig. S10) with no net spin were employed for theoretical calculations, in which a typical defect (i.e., 585 defect or pentagon defect) [21,23,27] was modeled at the edge of carbon cluster. The control model (C, see Fig. S11) containing a pyridinic $\mathrm{N}$ was also used for comparison. All model structures were optimized at the M06-2X/3-21G level [50,51] in vacuum and confirmed by vibrational analysis as local-energy minima. The products obtained via key steps of ORR correspond to the lowest calculated potential energy. To evaluate the Gibbs free energy change $\left(\Delta \mathrm{G}^{\circ}\right)$ before and after $\mathrm{O}_{2}$ activation, single-point calculations were carried out at the higher level of M06-2X/6-31++G** [52]. The calculated data of proton affinity are listed in Table S2. According to our calculations, there are two possible pathways toward the formation of $\mathrm{A}-\mathrm{O} \cdots \mathrm{OH}^{+}$(Fig. 7), the key intermediate of ORR: (i) protonation of $\mathbf{A}$ followed by $\mathrm{O}_{2}$ adsorption and activation; (ii) $\mathrm{O}_{2}$ adsorption to $\mathbf{A}$ followed by proton-induced activation. The calculated $\Delta \mathrm{G}^{\circ}$ for key steps of ORR for models A, B, C is summarized in Table S3. In either pathway, the defect edge carbon (i.e., C8) plays an important role as the active site, where $\mathrm{O}_{2}$ adsorption and activation favorably occur with the $\Delta \mathrm{G}^{\circ}$ of $-8.8 \sim-13.6 \mathrm{kcal} \mathrm{mol}^{-1}$ (see. However, if a 
simplification of model A with just one pentagon is considered (i.e., model B), the calculations demonstrate the pentagon carbon (i.e., C17) as the most active site, yielding a higher $\Delta \mathrm{G}^{\circ}$ value of $-21.9 \sim \mathrm{Xx} \mathrm{kcal} \mathrm{mol}^{-1}$. As for model $\mathbf{C}$, the carbon (i.e., C17) next to the pyridinic $\mathrm{N}$ was revealed to be the most active site for $\mathrm{O}_{2}$ adsorption and activation, which is in good agreement with literature report [53-55]. The corresponding $\Delta \mathrm{G}^{\circ}$ was calculated to be $-17.8 \mathrm{kcal} \mathrm{mol}^{-1}$, higher than those of model A but lower than those of model $\mathbf{B}$. These results might indicate that the some carbon defect (i.e., 585-defect) can provide active site for ORR with a smaller activation barrier relative to that of pyridinic N-doped carbon, which might well account for the considerable ORR activity of the defective carbon D-PC-1(900) in acidic medium.

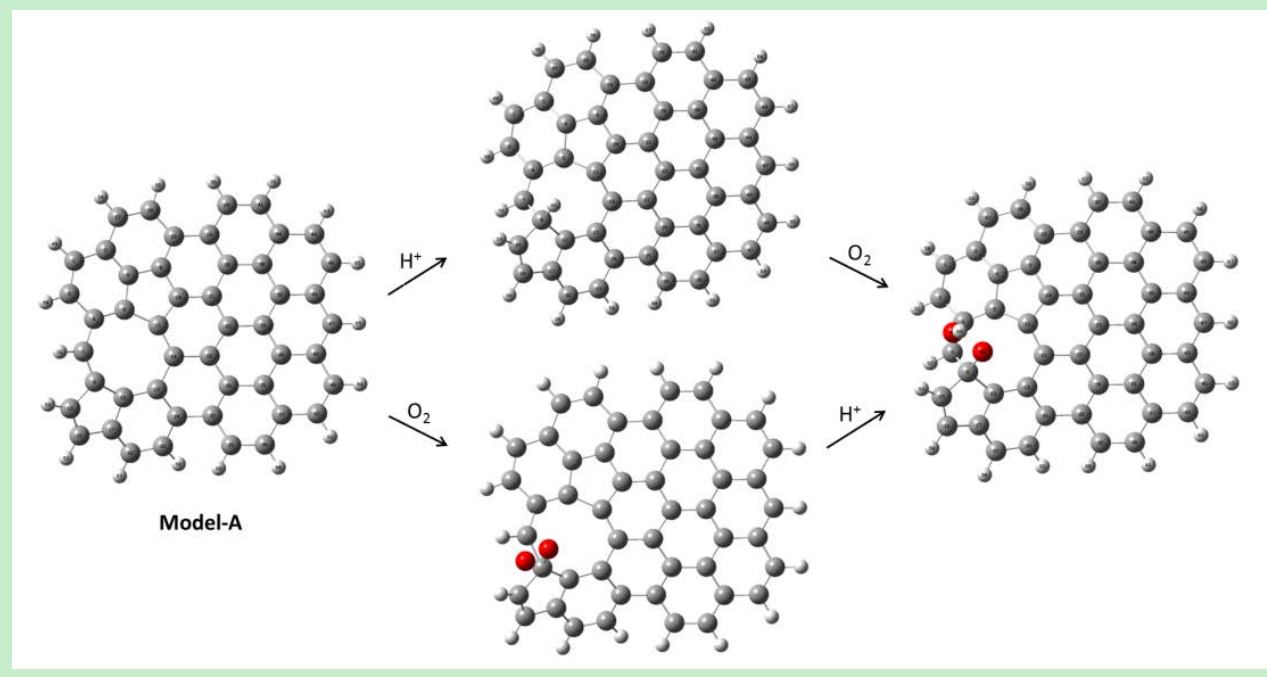

Figure 7. Schematic pathways toward the formation of $\mathrm{A}-\mathrm{O} \cdots \mathrm{OH}^{+}$.

\subsection{Long-term stability of defective carbon catalysts}

To evaluate the long-term stability of the as-prepared defective carbons, cycling durability tests were performed in both alkaline and acidic media. Particularly, after multiple CV cycles (i.e., 5000 cycles in alkaline medium and 2000 cycles in acidic medium) in a potential range of $0.6-1.0 \mathrm{~V}$ (vs. RHE) with a scan rate of $50 \mathrm{mV} \mathrm{s}^{-1}$, the 
$E_{1 / 2}$ of D-PC-1(900) undergoes only $7 \mathrm{mV}$ and $13 \mathrm{mV}$ negative shifts in alkaline and acidic media (Fig. 8), respectively. In contrast, the potential shift observed for Pt/C is more than $40 \mathrm{mV}$ under the same condition (Fig. S12). These results, therefore, indicate a better stability for D-PC-1(900) relative to that of Pt/C catalyst in either alkaline or acidic media. To confirm these results, chronoamperometric measurements were performed in both alkaline and acidic media. As shown in Fig. S13, D-PC-1(900) exhibits a good stability with a relatively small current decay (i.e., 5\%) over $5 \mathrm{~h}$ in alkaline or over $2.5 \mathrm{~h}$ in acidic medium. In comparison, $\mathrm{Pt} / \mathrm{C}$ catalyst shows a much lower stability with a more remarkable current decay (i.e., 20\% decay) under the same condition. Moreover, the resistance of D-PC-1(900) to methanol crossover was evaluated by the chronoamperometric measurements at a rotating rate of $1600 \mathrm{rpm}$ in $0.1 \mathrm{M} \mathrm{KOH}$ and $0.5 \mathrm{M} \mathrm{H}_{2} \mathrm{SO}_{4}$, respectively. As shown in Fig. 9, D-PC-1(900) shows a small current decay (7-15\%) upon the addition of 3M methanol into the electrolyte, irrespective of alkaline or acidic medium, while $\mathrm{Pt} / \mathrm{C}$ displays a remarkable current drop of ca. 40-70\% upon the methanol addition. These results thus suggest a better methanol tolerance for D-PC-1(900) in both alkaline and acidic media.
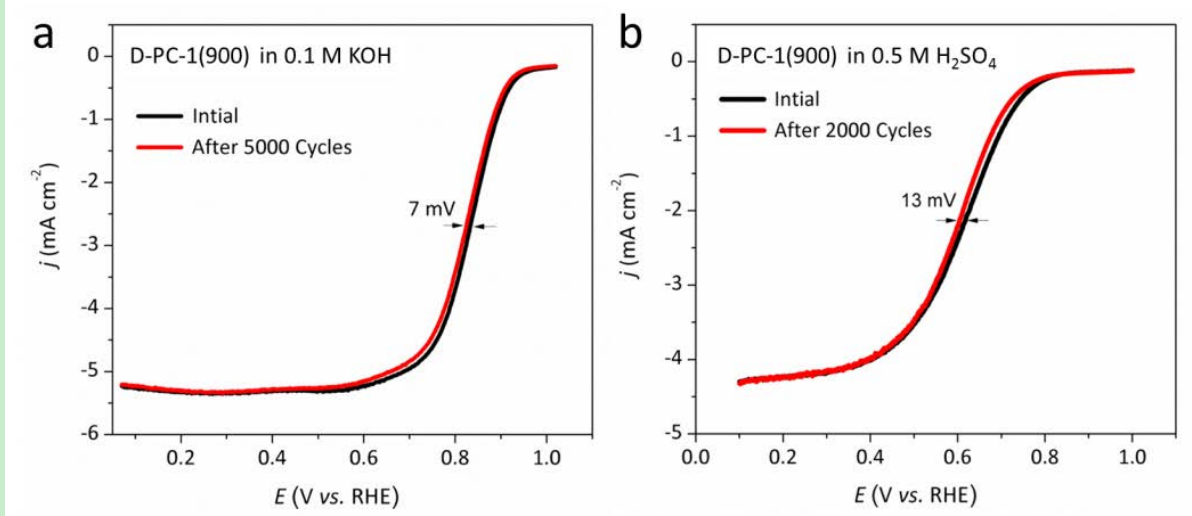
Figure 8. LSV curves of D-PC-1(900) in $\mathrm{O}_{2}$-saturated (a) $0.1 \mathrm{M} \mathrm{KOH}$ and (b) $0.5 \mathrm{M}$ $\mathrm{H}_{2} \mathrm{SO}_{4}$ solutions, respectively, before and after 5000 or $2000 \mathrm{CV}$ cycles between 0.6-1.0 V and 0.4-0.8 V vs RHE.
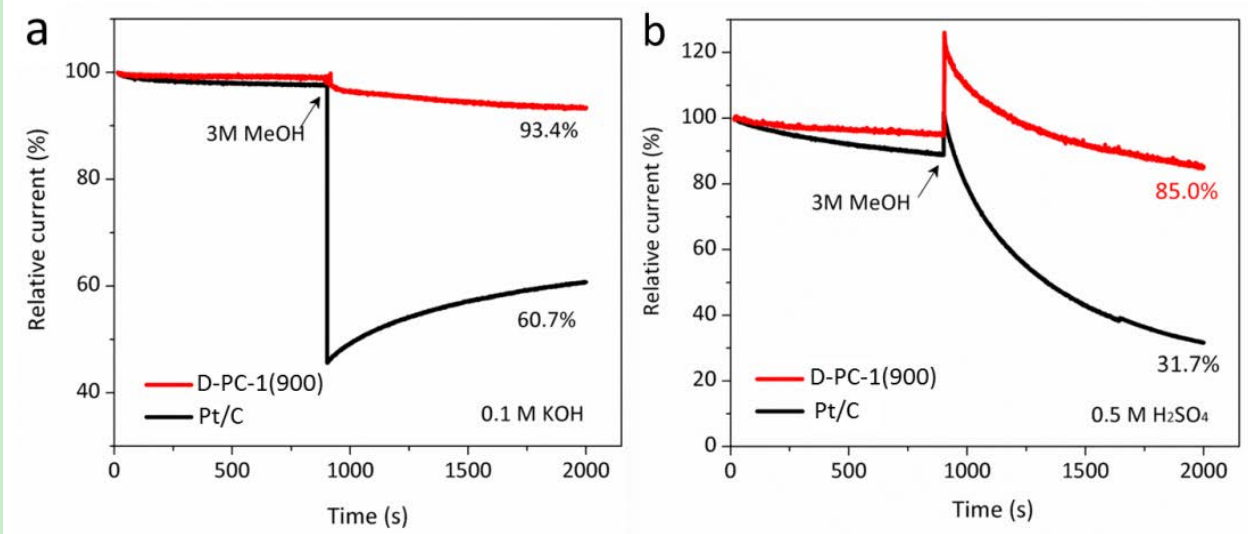

Figure 9. i-t chronoamperometric responses of the catalyst-modified electrodes upon the addition of methanol at $0.6 \mathrm{~V}$ (vs RHE) with a rotating speed of $1600 \mathrm{rpm}$ in $\mathrm{O}_{2}$-saturated (a) $0.1 \mathrm{M} \mathrm{KOH}$ and (b) $0.5 \mathrm{M} \mathrm{H}_{2} \mathrm{SO}_{4}$, respectively. The arrow indicates the addition of methanol into the electrolytic cell.

\section{Conclusions}

In summary, a series of defective carbon catalysts were prepared via a simple and scalable "N-doping-removal" approach using abundant seaweed biomass SA as precursor. The systematic studies give rise to the following guidelines: (i) the “N-doping-removal” process is essential in achieving the ORR-active defects; (ii) the defect content, porosity characteristics and conductivity of defective carbon are highly related to the pyrolysis temperature and viscosity of precursor polymer SA; (iii) the optimized defective carbon D-PC-1(900) was obtained via the pyrolysis at $900{ }^{\circ} \mathrm{C}$ using the SA with medium viscosity as precursor, which features negligible N-content, abundant ORR-active defects, a high BET surface area $\left(1377 \mathrm{~m}^{2} \mathrm{~g}^{-1}\right)$ with a $\mathrm{S}_{\text {micro }} /$ meso 
ratio of 0.6 and good conductivity. In $0.1 \mathrm{M} \mathrm{KOH,} \mathrm{D-PC-1(900)} \mathrm{exhibits} \mathrm{excellent}$ ORR activity in terms of an $E_{1 / 2}$ of $0.83 \mathrm{~V}$ ( $v s \mathrm{RHE}$ ), comparable to that of $\mathrm{Pt} / \mathrm{C}$ catalyst. In $0.5 \mathrm{M} \mathrm{H}_{2} \mathrm{SO}_{4}$, this catalyst also exhibits considerable ORR activity in terms of an $E_{1 / 2}$ of $0.63 \mathrm{~V}$ (vs RHE), which is among the best reported for defective carbons and comparable to many of $\mathrm{N}$-doped carbon catalysts. DFT calculations confirm that the carbon defect can create the active site for ORR in acidic medium. Moreover, experimental results reveal that D-PC-1(900) follows the direct $4 \mathrm{e}^{-}$ pathway, indicating efficient reductions of $\mathrm{O}_{2}$ to water in both alkaline and acidic conditions. The catalyst also shows superior stability and methanol tolerance relative to those of $\mathrm{Pt} / \mathrm{C}$ catalyst. All these results demonstrate that D-PC-1(900) is an excellent candidate for non-precious-metal ORR catalyst in fuel cells. This work also provides more insights to fabricate highly efficient defective carbon catalysts for the ORR in both alkaline and acidic media.

\section{Acknowledgements}

This work is supported in part by the Natural Science Foundation of China (51372158, 51772195) and Suzhou Key Laboratory for Advanced Carbon Materials and Wearable Energy Technologies. 


\section{References}

[1]. D. Wang, H.L. Xin, R. Hovden, H. Wang, Y. Yu, D.A. Muller, F.J. DiSalvo, D. A. Hector, Structurally ordered intermetallic platinum-cobalt core-shell nanoparticles with enhanced activity and stability as oxygen reduction electrocatalysts, Nat. Mater. 12 (1) (2013) 81-87.

[2]. J. Wang, J. Hao, D. Liu, S. Qin, D. Portehault, Y. Li, Y. Chen, W. Lei, Porous boron carbon nitride nanosheets as efficient metal-free catalysts for the oxygen reduction reaction in both alkaline and acidic solutions, ACS Energy Lett. 2 (2) (2017) 306-312.

[3]. J. Suntivich, H.A. Gasteiger, N. Yabuuchi, H. Nakanishi, J.B. Goodenough, Y. Shao-Horn, Design principles for oxygen-reduction activity on perovskite oxide catalysts for fuel cells and metal-air batteries, Nat. Chem. 3 (7) (2011) 546-550.

[4]. F. Cheng, J. Chen, Metal-air batteries: from oxygen reduction electrochemistry to cathode Catalysts, Chem. Soc. Rev. 41(6) (2012) 2172-2192.

[5]. Y. Nie, L. Li, Z. Wei, Recent advancements in Pt and Pt-free catalysts for oxygen reduction reaction, Chem. Soc. Rev. 44 (8) (2015) 2168-2210.

[6]. M. Zhou, H. Wang, S. Guo, Towards high-efficiency nanoelectrocatalysts for oxygen reduction through engineering advanced carbon nanomaterials, Chem. Soc. Rev. 45 (5) (2016) 1273-1307.

[7]. M. Shao, Q. Chang, J.-P. Dodelet, R. Chenitz, Recent advances in electrocatalysts for oxygen reduction reaction, Chem. Rev. 116 (6) (2016) 3594-3657.

[8]. K. Gong, F. Du, Z. Xia, M. Durstock, L. Dai, Nitrogen-doped carbon nanotube arrays with high electrocatalytic activity for oxygen reduction, Science 323 (5915) (2009) 760-764. 
[9]. C. Zhang, B. Wang, X. Shen, J. Liu, X. Kong, Steven S.C. Chuang, D. Yang, A. Dong, Z. Peng, A nitrogen-doped ordered mesoporous carbon/graphene framework as bifunctional electrocatalyst for oxygen reduction and evolution reactions, Nano Energy 30 (2016) 503-510.

[10]. K.P. Singh, E.J. Bae, J.S. Yu, Fe-P: a new class of electroactive catalyst for oxygen reduction reaction, J. Am. Chem. Soc. 137 (9) (2015) 3165-3168.

[11]. J.T. Zhang, Z.H. Zhao, Z.H. Xia; L.M. Dai, A metal-free bifunctional electrocatalyst for oxygen reduction and oxygen evolution reactions, Nat. Nanotechnol. 10 (5) (2015) 444-452.

[12]. Z.L. Ma, S. Dou,; A.L. Shen, L. Tao, L.M. Dai, S.Y. Wang, Sulfur-doped Graphene derived from cycled lithium-sulfur batteries as a metal-free electrocatalyst for the oxygen reduction reaction, Angew. Chem. Int. Ed. 54 (6) (2015) 1888-1892.

[13]. A.M. El-Sawy, I.M. Mosa, D. Su, C.J.S. Guild, Khalid, R. Joesten, J.F. Rusling, S.L. Suib, Controlling the active sites of sulfur-doped carbon nanotube-graphene nanolobes for highly efficient oxygen evolution and reduction catalysis, Adv. Energy Mater. 6 (5) (2016) 1501966

[14]. Y. Zhao, L.J. Yang, S. Chen, X.Z. Wang, Y.W. Ma, Q. Wu, Y.F. Jiang, W.J. Qian, Z. Hu, Can boron and nitrogen co-doping improve oxygen reduction reaction activity of carbon nanotubes? J. Am. Chem. Soc. 135 (4) (2013) 1201-1204.

[15]. T. Van Tam, S.G. Kang, K.F. Babu, E.-S. Oh, S.G. Lee, W.M. Choi, Synthesis of b-doped graphene quantum dots as a metal-free electrocatalyst for the oxygen reduction reaction, J. Mater. Chem. A 5 (21) (2017) 10537-10543. 
[16]. J.C. Li, P.X. Hou, S.Y. Zhao, C. Liu, D.M. Tang, M. Cheng, F. Zhang, H.M. Cheng, A 3D bi-functional porous $\mathrm{N}$-doped carbon microtube sponge electrocatalyst for oxygen reduction and oxygen evolution reactions, Energy Environ. Sci. 9 (10) (2016) 3079-3084.

[17]. B.Y. Xia, Y. Yan, N. Li, H. Wu, X.W. Lou, X. Wang, A metal-organic framework-derived bifunctional oxygen electrocatalyst, Nature Energy 1 (2016) 1-8.

[18]. S.N. Bhange, S.M. Unnia, S. Kurungot, Nitrogen and sulphur co-doped crumbled graphene for the oxygen reduction reaction with improved activity and stability in acidic medium, J. Mater. Chem. A 4 (16) (2016) 6014-6020.

[19]. J.J. Li, Y.M. Zhang, X.H. Zhang, J.Z. Huang, J.C. Han, Z.H. Zhang, X.J. Han, P. $\mathrm{Xu}, \mathrm{B}$. Song, S, N dual-doped graphene-like carbon nanosheets as efficient oxygen reduction reaction electrocatalysts, ACS Appl. Mater. Interfaces 9 (1) (2017) 398-405.

[20]. K. Waki, R.A. Wong, H.S. Oktaviano, T. Fujio, T. Nagai, K. Kimotob, K. Yamada, Non-nitrogen doped and non-Metal oxygen reduction electrocatalysts based on carbon nanotubes: mechanism and origin of ORR activity, Energy Environ. Sci. 7 (6) (2014) 1950-1958.

[21]. H.Y. Zhao, C.H. Sun, Z. Jin, D.W. Wang, X.C. Yan, Z.G. Chen, G.S. Zhu, X.D. Yao, Carbon for the oxygen reduction reaction: a defect mechanism, J. Mater. Chem. A 3 (22) (2015) 11736-11739.

[22]. Y.F. Jiang, L.J. Yang, T. Sun, J. Zhao, Z.Y. Lyu, O. Zhuo, X.Z. Wang, Q. Wu, J. Ma, Z. Hu, Significant contribution of intrinsic carbon defects to oxygen reduction activity, ACS Catal. 5 (11) (2015) 6707-6712. 
[23]. L.P. Zhang, Q. Xu, J.B. Niu, Z. H. Xia, Role of lattice defects in catalytic activities of graphene clusters for fuel cells, Phys. Chem. Chem. Phys. 17(26) (2015) 16733-16743.

[24]. H.L. Jin, H.H. Huang, Y.H. He, X. Feng, S. Wang, L.M. Dai, J.C. Wang, Graphene quantum dots supported by graphene nanoribbons with ultrahigh electrocatalytic performance for oxygen reduction. J. Am. Chem. Soc. 137 (24) (2015) 7588-7591.

[25]. X.J. Zhao, X.Q. Zou, X.C. Yan, C.L. Brown, Z.G. Chen, G.S. Zhu, X.D. Yao, Defect-driven oxygen reduction reaction (ORR) of carbon without any element doping, Inorg. Chem. Front. 3 (3) (2016) 417-421.

[26]. X.C. Yan, Y. Jia, T. Odedairo, X.J. Zhao, Z. Jin, Z.H. Zhu, X.D. Yao, Activated carbon becomes active for oxygen reduction and hydrogen evolution reactions, Chem. Commun. 52 (52) (2016) 8156-8159.

[27]. Y. Jia, L.Z. Zhang, A.J. Du, G.P. Gao, J. Chen, X.C. Yan, C.L. Brown, X.D. Yao, Defect graphene as a trifunctional catalyst for electrochemical reactions, Adv. Mater. 28 (43) (2016) 9532-9538.

[28]. C.H. You, X.W. Jiang, L.Y. Han, X.H. Wang, Q. Lin, Y.J. Hua, C.T. Wang, X.L. Liu, S.J. Liao, Uniform nitrogen and sulphur co-doped hollow carbon nanospheres as efficient metal-free electrocatalysts for oxygen reduction, J. Mater. Chem. A 5 (4) (2017) $1742-1748$.

[29]. Y.Y. Liu, H.L. Jiang, Y.H. Zhu, X.L. Yang, C.H. Li, Transition metals (Fe, Co, and $\mathrm{Ni}$ ) encapsulated in nitrogen-doped carbon nanotubes as bi-functional catalysts for oxygen electrode reactions, J. Mater. Chem. A 4 (5) (2016) 1694-1701. 
[30]. C.H. Xiao, X. Chen, Z.Y. Fan, J. Liang, B. Zhang, S.J. Ding, Surface-nitrogen-rich ordered mesoporous carbon as an efficient metal-free electrocatalyst for oxygen reduction reaction, Nanotechnology 27 (44) (2016) 1-10.

[31]. S.B. Yang, X.L. Feng, X.C. Wang, K. Müllen, Graphene-based carbon nitride nanosheets as efficient metal-free electrocatalysts for oxygen reduction reactions, Angew. Chem. Int. Ed. 50 (23) (2011) 5339-5343.

[32]. S. Ratso, I. Kruusenberg, A. Sarapuu, M. Kook, P. Rauwel, R. Saar, J. Aruväli, K. Tammeveskia, Electrocatalysis of oxygen reduction on iron- and cobalt-containing nitrogen-doped carbon nanotubes in acid media, Electrochim. Acta 218 (2016) 303-310.

[33]. C.J. Xuan, Z.X. Wu, W. Lei, J. Wang, J.P. Guo, D.L. Wang, Nitrogen-doped hierarchical porous carbons derived from sodium alginate as efficient oxygen reduction reaction, Electrocatalysts Chemcatchem 9 (5) (2017) 809-815.

[34]. M. Latorre-Snchez, A. Primo, H. García, P-doped graphene obtained by pyrolysis of modified alginate as a photocatalyst for hydrogen generation from water-methanol mixtures, Angew. Chem. Int. Ed. 52 (45) (2013) 11813-11816.

[35]. N. Ma, Y. Jia, X.F. Yang, X.L. She, L.Z. Zhang, Z. Peng, X.D. Yao, D. J. Yang, Seaweed biomass derived (Ni,Co)/CNT nanoaerogels: efficient bifunctional electrocatalysts for oxygen evolution and reduction reactions, J. Mater. Chem. A 4 (17) (2016) 6376-6384.

[36]. D.H. Li, C.X. Lv, L. Liu, Y.Z. Xia, X.L. She, S.J. Guo, D.J. Yang, Egg-box structure in cobalt alginate: a new approach to multifunctional hierarchical mesoporous 
$\mathrm{N}$ doped carbon nanofibers for efficient catalysis and energy storage, ACS Cent. Sci. 1 (5) (2015) 261-269.

[37]. H. Ba, Y. Liu, L. Truong-Phuoc, C.D. Viet, J.-M. Nhut, D.-L. Nguyen, O. Ersen, G. Tuci, G. Giambastiani; C. Pham-Huu, N-doped food-grade-derived 3D mesoporous foams as metal-free systems for catalysis, ACS Catal. 6 (3) (2016) 1408-1419.

[38]. C.Z. Guo, W.L. Liao, Z.B. Li, L.T. Sun, C.G. Chen, Easy conversion of protein-rich enoki mushroom biomass to a nitrogen-doped carbon nanomaterial as a promising metal-free catalyst for oxygen reduction reaction, Nanoscale 7 (38) (2015) 15990-15998.

[39]. Y. Gong, H. Fei, X. Zou, W. Zhou, S. Yang, G. Ye, Z. Liu, Z. Peng, J. Lou, R. Vajtai, B.I. Yakobson, J.M. Tour, P.M. Ajayan, Boron- and nitrogen-substituted graphene nanoribbons as efficient catalysts for oxygen reduction reaction, Chem. Mater. 27 (4) (2015) 1181-1186.

[40]. A.C. Ferrari, J. Robertson, Interpretation of raman spectra of disordered and amorphous carbon, Phys. Rev. B 61 (20) (2000) 14095-14107.

[41]. O. Akhavan, The effect of heat treatment on formation of graphene thin films from graphene oxide nanosheets, Carbon 48 (2) (2010) 509-519.

[42]. L. Lin, Q. Zhu, A.-W. Xu, Noble-metal-free Fe-N/C catalyst for highly efficient oxygen reduction reaction under both alkaline and acidic conditions, J. Am. Chem. Soc. 136 (31) (2014) 11027-11033. 
[43]. M. Acik, G. Lee, C. Mattevi, M. Chhowalla, K. Cho, Y.J. Chabal, Unusual infrared absorption mechanism in thermally reduced graphene oxide, Nat. Mater. 9 (10) (2010) 840-845.

[44]. D.H. Li, D.J. Yang, X.Y. Zhu, D.W. Jing, Y.Z. Xia, Q. Ji, R.S. Cai, H. L. Li, Y.K. Che, Simple pyrolysis of cobalt alginate fibres into Co3O4/C nano/microstructures for a high-performance lithium ion battery anode, J. Mater. Chem. A 2(44) (2014) 18761-18766.

[45]. Z.X. Wu, R. Liu, J. Wang, J. Zhu, W.P. Xiao, C.J. Xuan, W. Lei, D.L. Wang, Nitrogen and sulfur co-doping of 3D hollow-structured carbon spheres as an efficient and stable metal free catalyst for the oxygen reduction reaction, Nanoscale 8 (45) (2016) 19086-19092.

[46]. L. Wang, S. Dou, J.T. Xu, H.K. Liu, S.Y. Wang, J.M. Ma, S.X. Dou, Highly nitrogen doped carbon nanosheets as an efficient electrocatalyst for the oxygen reduction reaction, Chem. Commun. 51 (59) (2015) 11791-11794.

[47]. X.Z. Li, Y.Y. Fang, S.L. Zhao, J.T. Wu, F. Li, M. Tian, X.F. Long, J. Jin, J.T. Ma, Nitrogen-doped mesoporous carbon nanosheet/carbon nanotube hybrids as metal-free bi-functional electrocatalysts for water oxidation and oxygen reduction, J. Mater. Chem. A 4 (34) (2016) 13133-13141.

[48]. X.C. Cao, C. Jin, F.L. Lu, Z.R. Yang, M. Shen, R.Z. Yang, Electrochemical properties of $\mathrm{MnCo}_{2} \mathrm{O}_{4}$ spinel bifunctional catalyst for oxygen reduction and evolution reaction, J. Electrochem. Soc. 161 (5) (2014) H296-H300. 
[49]. M.J. Frisch, G.W. Trucks, H.B. Schlegel, G.E. Scuseria, M.A. Robb, J.R. Cheeseman, G. Scalmani, V. Barone, B. Mennucci, G.A. Petersson, H. Nakatsuji, M. Caricato, X. Li, H.P. Hratchian, A.F. Izmaylov, J. Bloino, G. Zheng, J.L. Sonnenberg,; M. Hada, M. Ehara, K. Toyota, R. Fukuda, J. Hasegawa, M. Ishida, T. Nakajima, Y. Honda, O. Kitao, H. Nakai, T. Vreven, Jr. J.A. Montgomery, J. E. Peralta, F. Ogliaro, M. Bearpark, J.J. Heyd, E. Brothers, K.N. Kudin, V.N. Staroverov, R. Kobayashi, J. Normand, K. Raghavachari, A. Rendell, J.C. Burant, S.S. Iyengar, J. Tomasi, M. Cossi, N. Rega, N.J. Millam, M. Klene, J.E. Knox, J.B. Cross, V. Bakken, C. Adamo, J. Jaramillo, R. Gomperts, R.E. Stratmann, O. Yazyev, A.J. Austin, R. Cammi, C. Pomelli, J.W. Ochterski, R.L. Martin, K. Morokuma, V.G. Zakrzewski, G.A. Voth, P. Salvador, J.J. Dannenberg, S. Dapprich, A.D. Daniels, O. Farkas, J.B. Foresman, J.V. Ortiz, J. Cioslowski, D.J. Fox, Gaussian 09, Rev. C.01, Gaussian Inc., Wallingford, CT 2013.

[50]. Y. Zhao, D.G. Truhlar, The M06 suite of density functionals for main group thermochemistry, thermochemical kinetics, noncovalent interactions, excited states, and transition elements: two new functionals and systematic testing of four M06-class functionals and 12 other functional, Theor. Chem. Acc. 120 (1-3) (2008) 215-241.

[51]. J.S. Binkley, J.A. Pople, W.J. Hehre, Self-consistent molecular orbital methods. 21. Small split-valence basis sets for first-row elements, J. Am. Chem. Soc. 102 (3) (1980) 939-947. 
[52]. W.J. Hehre, R. Ditchfield, J.A. Pople, Self-consistent molecular orbital methods. XII. Further extensions of Gaussian-type basis sets for use in molecular-orbital studies of organic molecules, J. Chem. Phys. 56 (5) (1972) 2257-2261.

[53]. M. Rauf, Y.-D. Zhao, Y.-C. Wang, Y.-P. Zheng, C. Chen, X.-D. Yang, Z.-Y. Zhou, S.-G. Sun, Insight into the different ORR catalytic activity of Fe/N/C between acidic and alkaline media: protonation of pyridinic nitrogen, Electrochemistry Communications 73 (2016) 71-74.

[54]. D. Guo, R. Shibuya, C. Akiba, S. Saji, T. Kondo, J. Nakamura, Active sites of nitrogen-doped carbon materials for oxygen reduction reaction clarified using model catalysts. Science 351 (6271) (2016) 361-365.

[55]. K. Mamtani, D. Jain, D. Zemlyanov, G. Celik, J. Luthman, G. Renkes, A.C. Co, U.S. Ozkan, Probing the oxygen reduction reaction active sites over nitrogen doped carbon nanostructures (CNx) in acidic media using phosphate anion. ACS Catal. 6 (10) (2016) 7249-7259. 